\title{
Macrosegregation Quality Criteria and Mechanical Soft Reduction for Central Quality Problems in Continuous Casting of Steel
}

\author{
Mostafa Omar El-Bealy \\ Companies Chair of Metals Processing \& Technology, MTC/Egypt, CTU/Germany, KTH/Sweden, MIT/USA, \\ Sweden Branch: Division of Casting of Metals, Department of Materials Science and Engineering, \\ Royal Institute of Technology, Stockholm, Sweden \\ Email: moelbealy@hotmail.com
}

Received 29 May 2014; revised 2 July 2014; accepted 22 July 2014

Copyright (C) 2014 by author and Scientific Research Publishing Inc. This work is licensed under the Creative Commons Attribution International License (CC BY). http://creativecommons.org/licenses/by/4.0/

(c) (i) Open Access

\begin{abstract}
In order to study the central quality of continuously cast tool steel slabs, the simple model has been developed to simulate the macrosegregation quality criteria. The model calculates different quality criteria such as average macro-segregation level criterion "ASL", its fluctuation level "FSL" and its segregation quality number "SQN". These criteria are calculated based on the previous measurements of carbon and sulfur concentrations distributions in final region of spray zones and centerline area of lower and upper slab sides. The effect of mechanical soft reduction Technique "MSR" on the slab centerline quality is examined and analyzed. The model results show that MSR affects the quality of centerline areas significantly by different ways based on the casting speed. The experimental and theoretical results clarify that the qualities of different slab sides are different for all collected samples. The model results show also that the accuracy of the macro-segregation quality criteria increases quantitatively with increasing the number of analyzed segregated elements. Therefore, the macrosegregation quality criteria and their distributions can be considered as the most simple and vital tool to evaluate the various slab qualities. Finally, the mechanism of centerline segregation formation with mechanical soft reduction is discussed in this study.
\end{abstract}

\section{Keywords}

Continuous Casting of Steel, Macrosegregation, Centerline Segregation, Macrosegregation Quality Criteria, Mechanical Soft Reduction Technique 


\section{Introduction}

Zero defects strategy of continuous casting is fundamental for reducing production costs, processing time and to assure reproducibility of the casting operation and increase of production. Quality, cost and timeliness of delivery have become the major drives of metals and materials production. The hard question, of course, is now how to maximize quality, minimize cost and optimize delivery. To seek answers, this cannot be achieved without a quality control and a greater knowledge about the process, incorporating both operational parameters, such as components of the machine, steel composition, pouring temperature and casting metallurgical constraints such as thickness of solidified shell at the mold exit and strand surface temperature profile along the different cooling zones. The use of optimization strategies such as genetic algorithm, heuristic search, knowledge base, working connected to mathematical models of solidification can be seen as useful tools in the search of operational parameters that it can maximize or minimize any aspect of the dynamic process.

The idea of using simulation to optimize a continuous caster is not just theoretical concept but it includes also practices. This idea has already been demonstrated by many investigators [1]-[11]. These and similar early models revealed important insights into the most frequent surface and internal defects [12]-[21]. For example, Samarasekera et al. [1] [2], have developed mathematical analyses of the thermal distortion of continuous casting billet molds and the influence of mold behavior on the production of these casters. Lally et al. [3] [4], have developed optimization strategies to determine parameters that maximize or minimize some aspects of a continuous casting process. El-Bealy and Fredriksson [5], have used the macrosegregation distributions of carbon to verify the heat flow phenomena in the mold zone in continuously cast steel billets. Meng and Thomas [6], have developed 1-D model of heat transfer and solidification of continuous slab casting to help the steelmakers to control the process. Li and Thomas [7], extend the model into 2-D thermo-mechanical finite element model of thermo-mechanical behavior of solid shell in continuous casting of steel. This is to avoid breakouts and the possibility to avoid interdendritic crack formation with maximization the casting speed. Zhu and Kumar [8], have been developed a mathematical modeling by combining heat transfer, steel shrinkage and parabolic continuous taper model in order to optimize the mold taper profile. They concluded that the optimum mold taper was a parabolic profile.

Several improved models of different heat transfer and solidification phenomena have been developed. ElBealy [9], extended the fluctuation macrosegregation technique to simulate mold heat transfer phenomena in addition to the microstructure evolution [5] [10]. The comparison between these phenomena reveals that the fluctuated macrosegregation technique is more accurate than the use of microstructure evolution technique. Nassar et al. [10], studied the growth irregularities during continuous casting caused by local variations in surface temperature due to the solidification behavior of $310 \mathrm{~S}$ stainless steel. They concluded that large variations in the surface temperature were expected due to the variation in heat extraction. This results in further shrinkages and then affects the growth of irregularities of solid shell. Manojlovie [11], proposed a mathematical model of dendritic solidification processes of continuously cast steel slabs. This was to optimize the continuous casting process variables and to improve the quality of slabs. This was by using a finite element method and also, by an analytical method applying isothermal method of Green's function. The comparison between the model predications of different methods solutions with real temperature measurements displays satisfying results in terms of appropriate determination of solidification process of steel slabs.

Many important related aspects of continuous casting have been modeled in depth and discussed elsewhere [12]-[21], including heat transfer [12] [13], solidification [14], fluid flow and the molten steel pool and inclusion removal [15], bulging and solid shell resistance of the strand [16] [17], crack predication [18]-[20], and quality criteria [21].

However, computational simulation and algorithms of industrial processes give important benefits to steel companies to reduce production cost and time. Some of authors have been worked on the controlling and automation of continuous casting processes and the development of continuously cast steel products and processes using expert systems and software [22]-[29]. An expert system for billet casting problems has been developed by Kumar et al. [22]. This is to guide caster operators in analyzing quality related problems and to provide them with a ready source of fundamental knowledge related to caster operation projected this expert system. Filipic and Saler [23], proposed and implemented a computational approach to the continuous casting of steel which consisted of a numerical simulator of the casting process and a genetic algorithm for real parameter optimization. Brimacombe [24], explained the importance and challenge of quality in continuous casting processes in details. Cheung and Garcia [25], as well as Santos et al. [26], have used a heuristic search technique for the optimization 
of the quality of carbon steel billets. Recently, Rabiser and hungana [27], added a tool-supported approach for integrated product configuration and requirements engineering. Kolev et al. [28], suggested a new global optimization method by using a discrete formulation in the form of the max flow-min cut framework of 3-D shape reconstruction. This was to study different energy methods for multi-view reconstruction and to compare. López et al. [29], described a development of powerful tool to analyze continuous casting process. This was by using computational algorithms based on numerical method to create a simulator for this process. This simulator functionally was shown and validated by comparing with industrial information of three steel production casters where a reasonable agreement was found.

Although, these models, software and expert systems have generated important insights and have helped much the steelmakers, they have not been established quantitatively, owing to the complexity of process variables and their interactions effects of many casting variables. In addition to this complexity, most of these techniques are very expansive, time consumes and not accurate for general uses to cover the differences between the steel casters [30]. There is still a need for better and more reliable models to gain more fast and quantitative insights into different qualities, defects formation and predications in continuous casting of steel.

Therefore, it is attempt in this paper to focus on the relationships between solidification defects formations and quality criteria of continuously cast tool steel slabs. Macrosegregation criteria such as average macrosegregation level criterion "ASL", its fluctuation level "FSL" and its segregation quality number "SQN" of carbon and sulfur segregates have been linked to central quality of upper and lower slab sides. Also, the different effects of mechanical soft reduction technique "MSR" on the central qualities are studied. Based on a quality mathematical model for individual segregated element or for average segregated elements, expressions have been developed explaining the quality differences as a purpose of preventing defects formations in continuous casting processes.

\section{Plant Trials and Metallurgical Study}

Plant trails were performed in slab caster 2 at SSAB Oxelösund AB, Sweden by Lagerstedt [31]. The layout of this caster is illustrated in Ref. [31]. The caster is bent with a radius of $8 \mathrm{~m}$ and the strand is straightened with liquid left in the centre. After $16 \mathrm{~m}$, the strand becomes horizontal.

Since plant trials focused on the effect of mechanical soft reduction technique on the level of centerline segregation, it is necessary to explain and to apply this technique in the right way [32]. Also, this technique should be applied by the right reduction magnitude and suitable casting speed. The roll alignment also should be well controlled [33].

Subsequently, the idea behind mechanical soft reduction technique "MSR" is to apply a certain pattern of the mechanical forces on the slab broad faces within the distance beneath the meniscus. This is by using pressure force of roll alignment against ferrostatic pressure as shown in Figure 1. This is to compensate the effect of slab bulging accumulated during secondary spray zones on the displacement formed in the central area. These forces

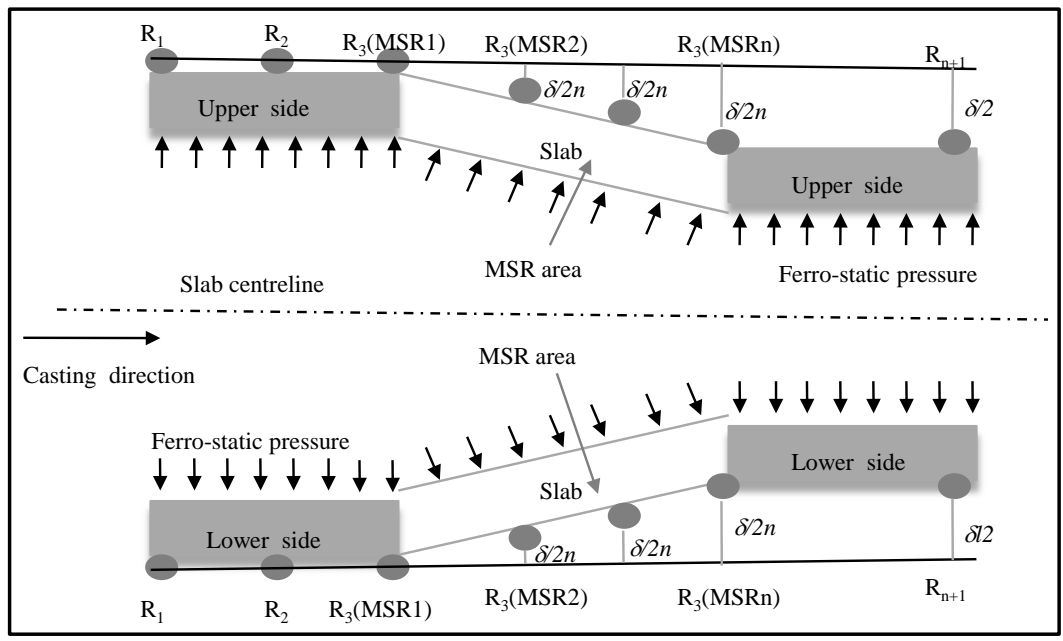

Figure 1. Schematic illustration of mechanical soft reduction technique. 
also to reduce the liquid pool width in central slab area to avoid sucking rich liquid downwards to replace the volume changes caused by thermal bulging of the slab [31] [32]. In these trails, MSR is situated between 22.9 and $27.9 \mathrm{~m}$ beneath the meniscus. The total reduction in the reduction zone defined by symbol $\delta$ in Figure 1 was $4 \mathrm{~mm}$ during the plant trials.

\subsection{Plant Trials}

Macrosegregation analyses were made during the casting of a large number of heats for which the details of steel composition, cutting and casting conditions are given in Table 1 and Table 2, respectively. All of steel grades examined were cast tool steel, with carbon content varying from 0.36 to 0.482 pct. Table 3 also shows the details of different cooling zones in the caster. The influences of other parameters such as casting speed and slab side on the macrosegregation distributions and therefore on the different quality criteria were explained and studied. In addition to measurements of carbon and sulfur segregations, the casting speed was recorded [31].

Table 1. Steel composition in weight percent for different group heats [31].

\begin{tabular}{ccccccccccc}
\hline $\mathrm{C} \%$ & $\mathrm{Si} \%$ & $\mathrm{Mn} \%$ & $\mathrm{P} \%$ & $\mathrm{~S} \%$ & $\mathrm{Cr} \%$ & $\mathrm{Ni} \%$ & $\mathrm{Mo} \%$ & $\mathrm{Cu} \%$ & $\mathrm{Al} \%$ & 0.008 \\
\hline 0.482 & 0.361 & 0.876 & 0.009 & 0.0479 & 1.49 & 0.048 & 0.013 & 0.035 \\
\hline
\end{tabular}

Table 2. Samples cutting and casting conditions [31].

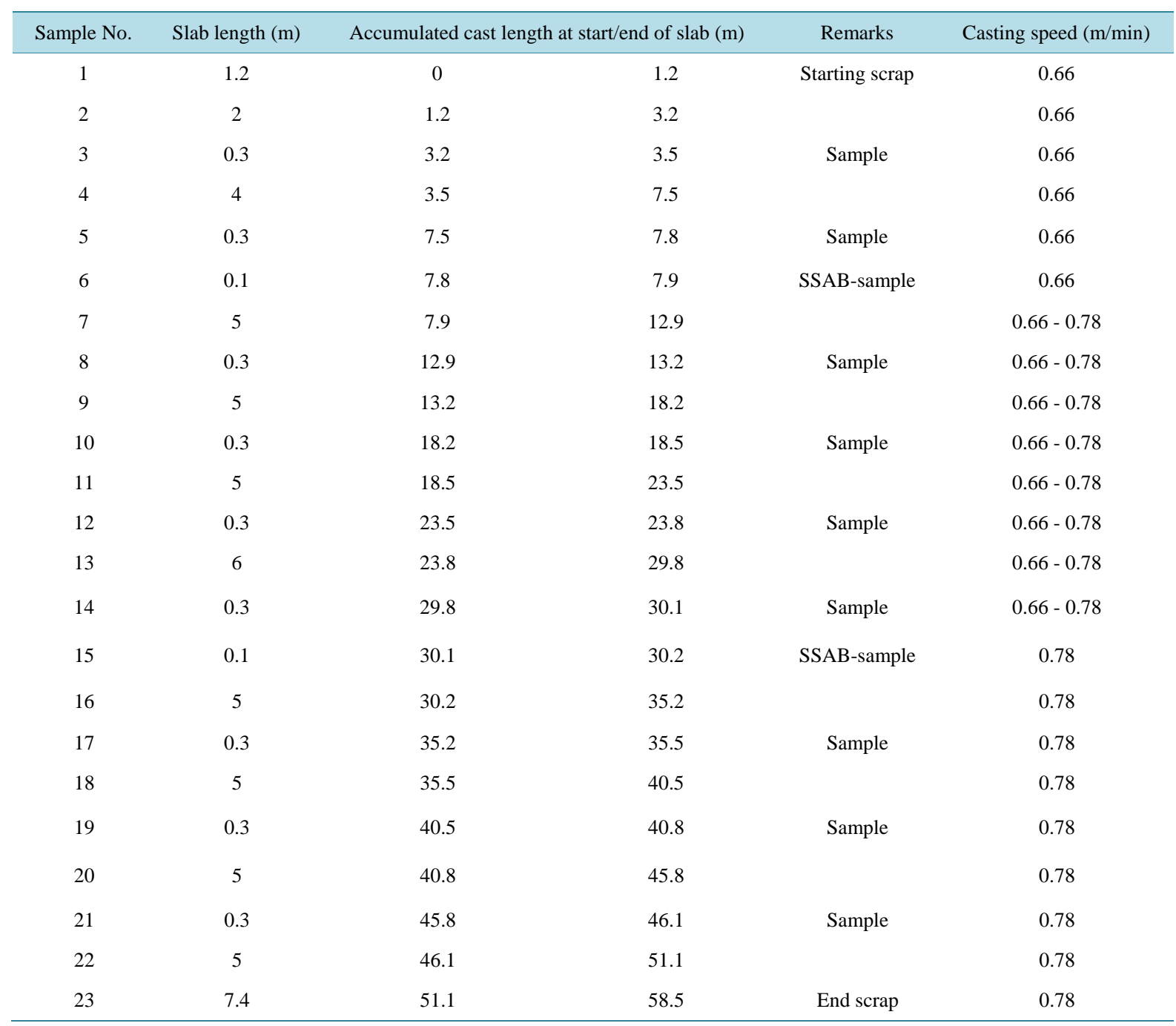


Table 3. Details of cooling zones of SSAB Oxelösund AB caster no. 2 [31].

\begin{tabular}{cccc}
\hline Distance from meniscus $(\mathrm{m})$ & Cooling type & Cooling water flow rate $(\mathrm{l} / \mathrm{min})$ & Remarks \\
\hline 0 & Mould & 60 & Copper \\
0.8 & Water spray & 220 & Straight vertical zone \\
3.5 & Roll cooling & 440 & Bent zone, $\mathrm{r}=8 \mathrm{~m}$ \\
12.9 & Roll cooling & 440 & Horizontal straightening zone \\
16.4 & & Horizontal zone \\
22.9 & & MSR starts \\
27.9 & & MSR ends \\
\hline
\end{tabular}

Furthermore, the slab samples were collected from selected heats during the plant trials for metallurgical investigation. These samples were divided into three different groups based on the casting speed magnitude [31]. The first group contains the samples which were casted by the constant casting speed of $0.66 \mathrm{~m} / \mathrm{min}$. In the second group, the casting speed changes from lower value of $0.66 \mathrm{~m} / \mathrm{min}$ to higher value of $0.78 \mathrm{~m} / \mathrm{min}$. Finally, the third group contains the samples which were casted by the constant casting speed value of $0.78 \mathrm{~m} / \mathrm{min}$. The metallurgical length should successively move downward into the zone of mechanical soft reduction. For each of the three patterns of casting speeds several samples have taken from the slab. Approximately $0.3 \mathrm{~m}$ from slab was cut out with the caster in-line flame cutter at positions along the slab according Table 3 [31].

\subsection{Metallurgical Study and Measurements}

Since this study focused on slab-related central quality problems, it was appropriate to examine metallographically only samples which were cut from the middle of cross section of slab broad faces as shown in Figure 2(a). The oils and oxidized surface layers on the slab samples were first removed by sandblasting to reveal the existence of cast structure. Then, the collected samples from plant trails were machined flat, grinded. Samples then were macroetched in a $50 \mathrm{pct}$ hydrochloric acid solution at $70^{\circ} \mathrm{C}$ [34]. The macrostructures were examined for the morphology of cast structure. Also, the fractions of columnar crystals (CCZ) and equiaxed crystal zone (EQZ) were measured by linear analysis technique from macroetched samples.

Samples then were cut into slices of $20 \times 20 \times 145 \mathrm{~mm}$ from the samples of different slab sides as shown in Figure 2(b). Carbon and sulfur concentrations then were determined by using chemical analysis of slices taken from collected slabs samples. A thin layer as shown in Figure 2(c) was removed from these slices by milling machine under suitable cutting conditions. This is to minimize the rising chip temperature and therefore reduce the effect of reheating chip on the carbon concentration [31] [32] [35]. Although, this technique is very accurate and experimentally represents definitely the macrosegregation distributions of different elements but it is slow and expansive. The dimensions of these layers were $20 \times 20 \times 1$ uniformly and continuously from $20 \mathrm{~mm}$ from slab centerline until the centerline of slab [31] [32] [35]. This is to obtain five chip pieces of chemical analysis and takes their mean average of every layer. The carbon and sulfur concentrations of the chip samples were determined by the laboratory at SSAB Oxelösund AB, Sweden. The macrosegregation ratios are given in Equation [1] for measurements of carbon and sulfur consternations with distance from slab centerline.

$$
S_{j}=\frac{\text { actual composition of } j\left(\chi_{\text {mea }_{j}}\right)}{\text { nominal composition of } j\left(\chi_{o_{j}}\right)}
$$

where $S_{j}$ in Equation [1] is macrosegregation ratio of element $j$.

\section{Experimental Results \& Analysis}

The typical macrostructures of collected samples are shown in macrographs 3 (a, b). All samples collected from plant trials show that the cast structure consists of mainly columnar crystals and a small equiaxed crystal zone along the centerline axis. The fraction of EQZ varies from 5\% to 9\% based on the operating and MSR conditions. EQZ is somewhat displaced towards the upper side of the strand where this nature since equiaxed crystals 


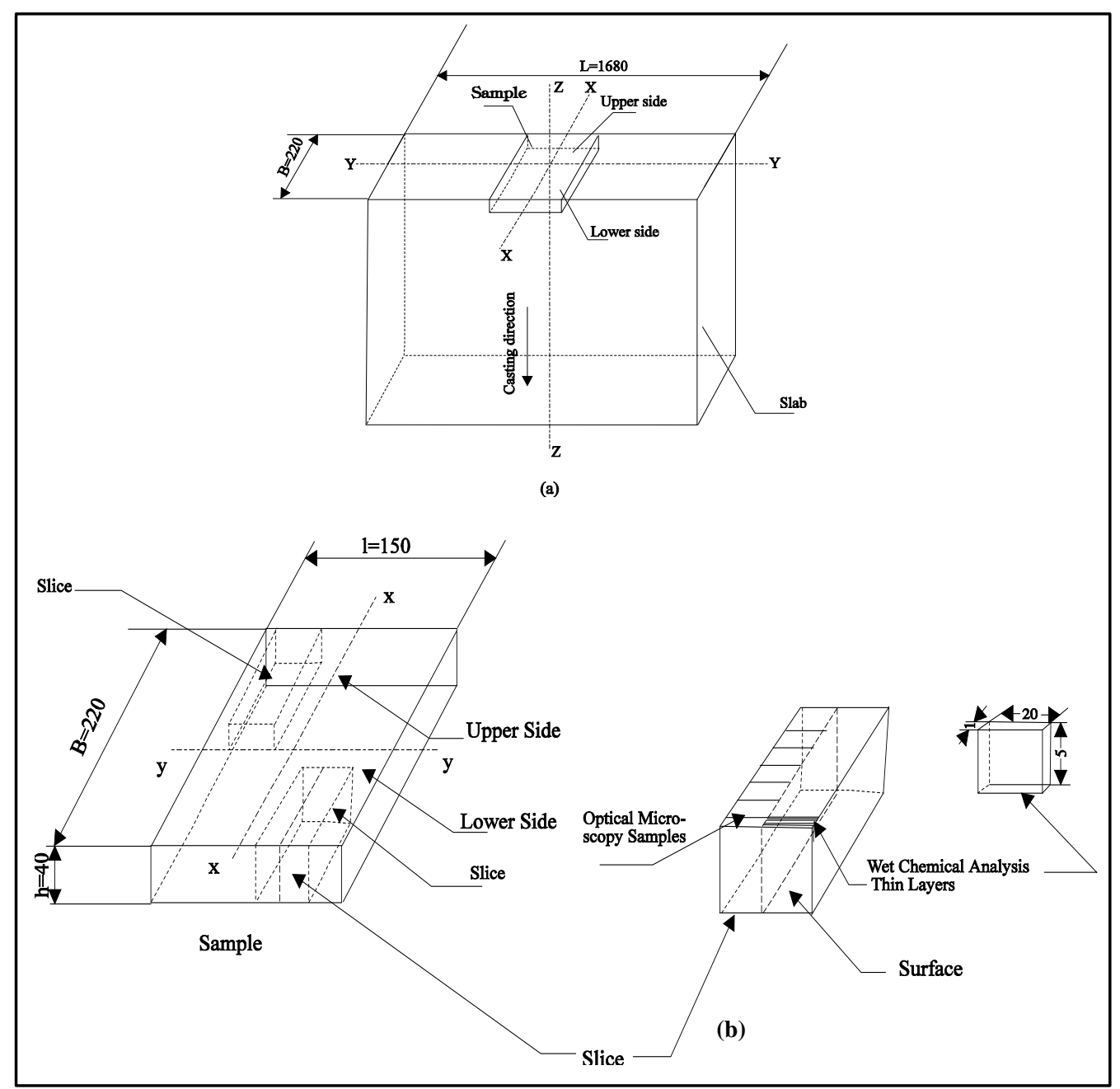

Figure 2. Sectioning of sample (a) slab sample location, (b) specimen location and (c) segregation layer for analysis and examination [12] [15].

sediment when the strand turns horizontal. These agree well with findings of Alberny and Birat [36], and Westin [37]. They found that the dimensions of the cast section are considerably influence the type of crystal and its fraction. Therefore, it must have an important effect on the resultant centerline segregation. From a metallurgical point of view, they concluded also that it is desirable to cast with large section size. This allows a longer solidification time, thereby eliminating the superheat in the core long before solidification is complete. This will reduce the relative length of columnar zone and allow equiaxed crystals to form which results in a more uniform central condition.

The macrographs in Figure 3(a) and Figure 3(b) reveal also different centerline morphologies. In the first group sample, Figure 3(a) reveal that the centerline segregation morphology appears as a continuous segregated line running through the slab centerline. However, the third group sample shown in Figure 3(b) shows that this morphology appears as discontinuous small segregated porosity distributed randomly along the slab centerline area. Also, Figures 4(a)-(c) show the segregation patterns of final stage of spray zones and slab centerline region for first, second and third groups' samples, respectively [31]. Macrosegregation distributions shown in these figures are used to analyze the dendritic solidification phenomena in the final stages of continuous casting process and some of them are discussed hereafter.

\subsection{Group 1}

Figure 4(a) shows distributions of carbon $(C)$ and sulfur $(S)$ segregation ratios in the final stage of spray 


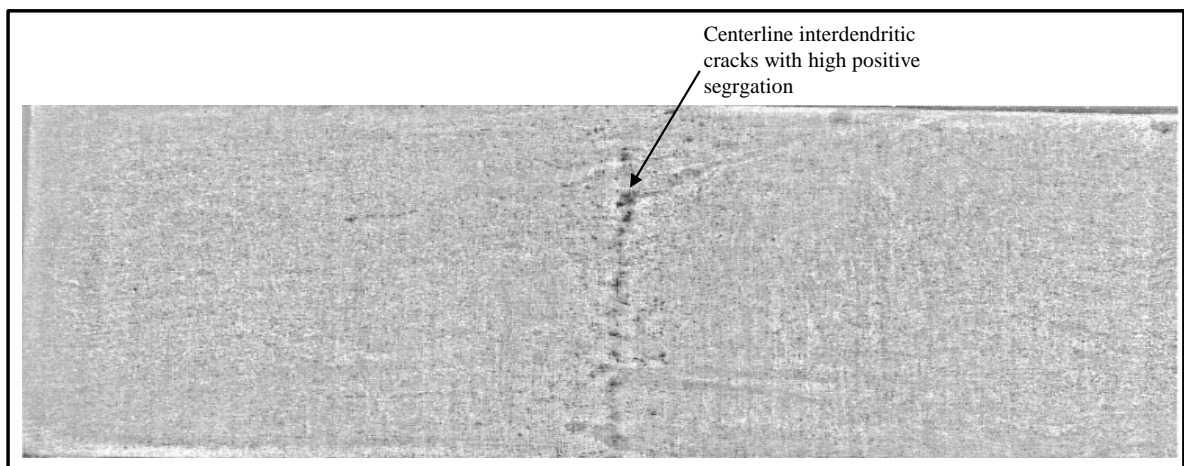

(a)

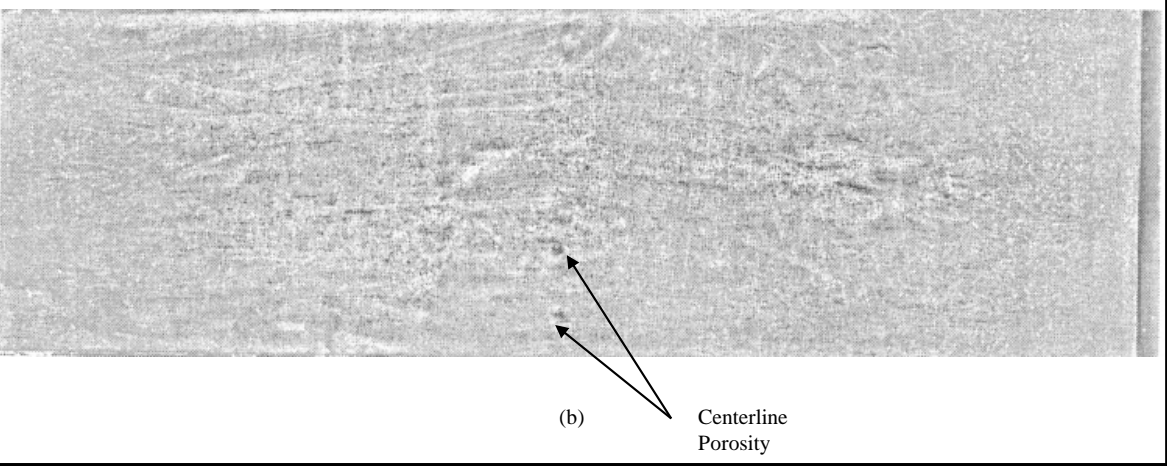

Figure 3. Macrographs of sample number (a) 6 and (b) 15 with casting speed 0.66 and 0.78 $\mathrm{m} / \mathrm{min}$, respectively [13].


Figure 4. Measured carbon and sulfur distributions in sample number 5 [31] [38]. 
zones and slab centerline region of group 1 conditions. This figure reveals that $C$ and $S$ segregates behave the same trend and fluctuate continuously and slightly in both slab sides in the final stage of spray zones. In the case of central region, $C$ segregation ratios of upper and lower sides follow the same trend whereas the clear difference is observed between $S$ segregation ratio patterns of different slab sides. This is due to a difference in interdendritic strain hypotheses between lower and upper slab sides and in partition coefficients of $C$ and $S$ [38]. The coupled effect of these factors controls the macrosegregation formation and its distributions. $C$ and $S$ segregation ratios then increase gradually $\left(S_{C}=1.093\right)$ and steeply $\left(S_{S}=1.55\right)$ in the slab centerline, respectively. This is associated with observed interdendritic crack with width value of $745 \mu \mathrm{m}$ as shown in Figure 3(a). These results point out also that the mechanical soft reduction "MSR" is not sufficient to affect the segregation patterns of different slab sides of central zone. This is due to a short liquid pool and unsuitable metallurgical length associated with low casting speed $0.66 \mathrm{~m} / \mathrm{min}$. This means that MSR cannot apply adequately [32].

Also, it is interesting to note that the segregation distributions of $C$ and $S$ shown in Figure 4(a) are sensitive to the different interdendritic strain hypotheses of upper and lower slab sides especially in the centerline zone. $C$ and $S$ segregates behave the same trend in the upper slab side where positive segregations of $C$ and $S$ increase by different rates until the slab centerline. This is because the solid shell starts to bulge in and pushes the mushy dendrites in the direction of slab center as shown in the flow pattern A in Figure 5 [17] [38]. This draws the solute liquid from above hotter region in the liquid pool into mushy zone just below the liquidus isotherm [38] [39]. This is results in a steep $S$ segregation and small $C$ segregation in the centerline zone of upper slab side illustrated in Figure 4(a). This flow pattern can be defined as squeezing mechanism.

However, the negative $C$ segregation reduces slightly in the central zone of lower slab side whereas the negative $S$ segregation increases gradually. Then, the negative segregates of $C$ and $S$ change suddenly into high positive segregations in the slab centerline, respectively. This results from bulging out of the slab solid shell which results in the mushy dendrites draw out and close the interdendritic areas between the dendrites. This sucks the interdendritic liquid to flow into slab centerline region against the high resistance of ferrostatic pressure and the slab weight as shown in flow pattern B in Figure 5 where this flow pattern can be characterized as sucking mechanism.

Another interesting phenomenon arises from the examinations of segregation distributions of $C$ and $S$ in the initial central slab region of both slab sides where the effect of segregation of $S$ on the partition coefficient of carbon for component $m$, in an $N$-component system $\left({ }^{N} K_{C}^{m}\right)$ becomes observed [40]. In the upper slab side, the squeezing mechanism A shown in Figure 5 helps to increase $S$ segregation in early stages of solidification. This is due to the nature of no diffusion mechanism of $S$ in dendritic solid and its small partition coefficient with

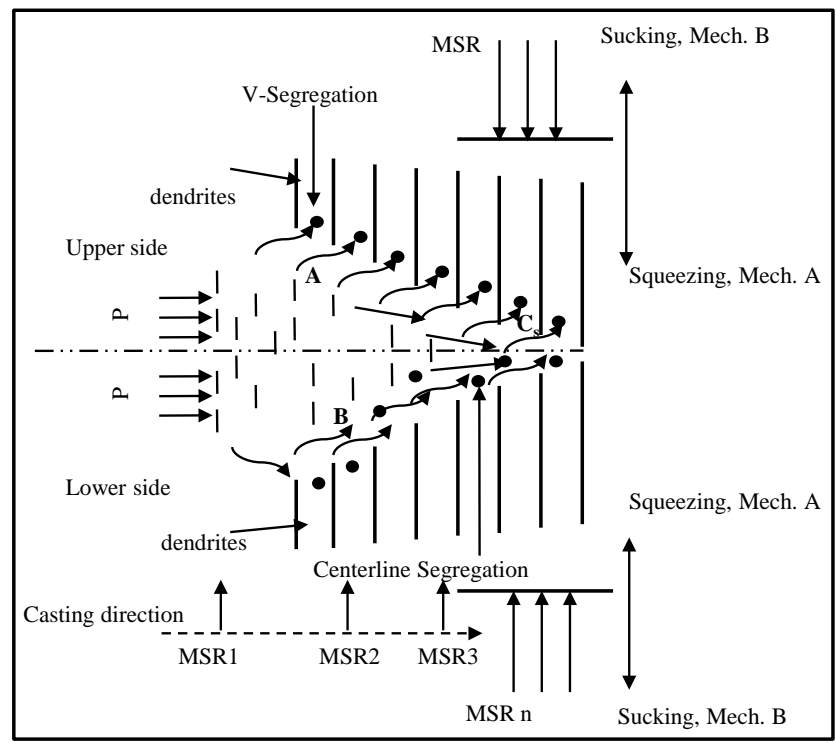

Figure 5. Schematic illustration of different flow patterns of squeezing and sucking processes [39]. 
iron. These result in an increasing in $S$ segregation in the interdendritic solute liquid between the dendrites [40]-[42]. This reduces $C$ segregation in the interdendritic solute liquid due to the positive effect of $S$ segregation on ${ }^{N} K_{C}^{m}$. Evidence of this conclusion, it can be seen it in $S$ and $C$ segregated distributions in the initial central region of lower slab side shown in Figure 4(a). The flow pattern B of sucking mechanism illustrated in Figure 5 reduces $S$ segregation level in the early stages of solidification. As solidification continues, $S$ segregation level gradually reduces. Then, the positive effect of negative segregation of $S$ in this case reduces ${ }^{N} K_{C}^{m}$. This affects $C$ segregation and results in a gradual increasing in its level as shown in Figure 4(a).

\subsection{Group 2}

Figure 4(b) illustrates $C$ and $S$ segregated distributions of second group where the casting speed changes from 0.66 into $0.78 \mathrm{~m} / \mathrm{min}$. This figure shows generally that the changing in the casting speed has different effects on the $C$ and $S$ segregation patterns in the final region of spray zones and central zone.

This effect has produced an observed reduction in the centerline segregation of $C$ and $S$. This is because the starting casting with low casting speed allows to increase the resistance against the thermo-mechanical stresses subjected to the slab solid shell during sprays zones [17] [40]. This will reduce the bulging level in the early spray zones and may allow decreasing the level of macrosegregation fluctuations with distance from slab surface [31]. Also, the low casting speed shortens the liquid pool length. With increasing the casting speed into $0.78 \mathrm{~m} / \mathrm{min}$, the liquid pool begins to lengthen. This changing in liquid pool length may increase the effective length of MSR. But, MSR starts lately to subject to the slab solid shell and its effect starts from roll MSR2 instead of MSR1 as shown in Figure 1. This produces an uncompleted effect of mechanical soft reduction on the centerline segregation of $C$ and $S$ [32].

However, the coupled effect of MSR and different interdendritic strain hypotheses on the segregated distributions of $C$ and $S$ of the upper and lower side is observed. This effect influences the bulging profiles between a pair of rolls as shown in Figure 6 and therefore affects the segregation patterns of $C$ and $S$ of slab sides by different ways as shown in Figure 4(b). In upper slab side, the positive segregation of $S$ fluctuates considerably and continuously in the final region of spray zones whereas the negative segregation of $C$ fluctuates slightly. This is due to a positive effect of $S$ segregation on the partition coefficient of $C$ and therefore on its segregation.

However, the reason behind the steep fluctuations of positive $S$ segregation can be clarified by analyzing the coupled effect of MSR and different interdendritic strain hypotheses on the bulging profile shown in Figure 6 [16] [43]. Figure 6 illustrates that the slab solid shell bulges in close to MSR1 roll and this pushes the mushy dendrites into the slab centerline. This results in a sudden squeezing of steel melt from hotter region in the liquid pool into interdendritic areas between the dendrites as illustrated in the squeezing mechanism A in Figure 5 . As slab moves, the solid shell bulges out based on the bulging line profile shown in Figure 6 and draws the dendrites away from slab centerline. This results in a gradual sucking of interdendritic liquid into slab centerline as shown in sucking mechanism B in Figure 5.

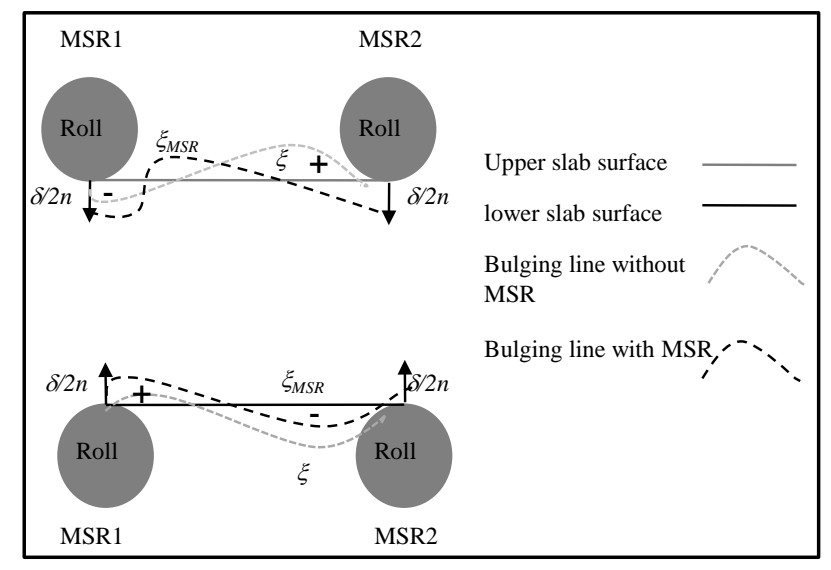

Figure 6. Schematic illustration of bulging lines without and with MSR of upper and lower sides [43]. 
Also, Figure 4(b) shows that the negative segregations of $S$ fluctuate observably in the lower slab side whereas small fluctuations of $C$ are observed. These results from two different reasons explained above. The first is the positive effect of $S$ on $C$ partition coefficient whereas the second one is coupled effect of squeezing and sucking mechanisms generated due to different bulging line profiles on the dendrites movement and therefore on the flow patterns in the interdendritic liquid and liquid pool as shown in Figure 5 and Figure 6.

\subsection{Group 3}

In the case of third group, the mechanical soft reduction "MSR" has produced a considered improvement in the centerline segregation of $C$ and $S$ as shown in Figure 4(c). In this case, the higher casting speed (0.78 $\mathrm{m} / \mathrm{min}$ ) lengthens liquid pool. This is due a suitable location to apply MSR which increases the magnitude of effective accumulative reduction into maximum value. This results from an increasing in the pushing amount of the mushy dendrites into the slab centerline. This mechanism closes the interdendritic spaces in slab centerline and sucks the rich solute liquid from liquid pool into the interdendritic spaces between the mushy dendrites. These reduce the centerline segregations of $C$ and $S$ significantly by different levels.

However, the segregated behaviors of $C$ and $S$ of slab upper and lower sides follow the same trend in final stage of spray zones and central region. In these regions, Figure 4(c) reveals that both of positive $S$ segregation and negative $C$ segregation ratios fluctuate continuously. The uniform behaviors of $C$ and $S$ fluctuations result from the reasons mentioned above in the analysis of first group. In addition to these reasons, the constant casting speed leads to increase the homogeneity degree of heat transfer between the rolls and reduces the levels of segregations fluctuations of $C$ and $S$ [38] [44] [45].

In general, the measured results of three group samples agree well with measurements and conclusions performed by Jacabsson et al., [32]. The only observed difference is between the present and Jacabsson et al. [32], measurements is due to a difference in solidification intervals between various peritectic steels. However, the proposed bulging profiles in Figure 6 agree well with calculations carried out by El-Bealy [40], who used bending theory and by Yn [43], who used a finite element method. In their stress analyses, they considered the rolls as continuous beams [46]. Also, the comparison between the predicted results of maximum bulging level computed by Yn [43], (6 - $7.5 \mathrm{~mm})$ and the total effective reduction used in the plant trails of this paper $(4 \mathrm{~mm})$ may gives an explanation about the incomplete effect of total effective reduction on the eliminating of centerline segregation. This comparison shows that the centerline segregation reductions accomplish $3.1 \%$ and $12.7 \%$ of the second group whereas in the case of the third group, these reductions reach $6.9 \%$ and $28.7 \%$ of $C$ and $S$ segregations, respectively. This means that the lengthening of total effective reduction improves the centerline segregation level. Subsequently, it may be concluded also that the total effective reduction to eliminate the centerline segregation may be greater than or equal the maximum bulging level.

\section{Quality Model Description}

In order to examine slab quality in various cooling zones of continuous casting of steel, macrosegregation criteria were developed based on El-Bealy approach explained in Ref. [21]. As result of complex segregation interactions of different alloying elements, this approach should be extended into multi segregated elements. Subsequently, the average segregation level "ASL" for individual segregated element $j$ can be computed by using the following Equation [21];

$$
\mathrm{ASL}_{j}=\frac{\sum_{1}^{n}\left|S_{j}-1\right|}{n}+1
$$

where $S_{j}$ in Equation (2) is macrosegregation ratio of the element $j$ element $j$ calculated by Equation [1] and $n$ is number of samples. All the symbols are defined in the nomenclature in the end of this paper. In the case of $m$ segregated elements, Equation (2) becomes as follows;

$$
\overline{\mathrm{ASL}}=\frac{\sum_{j=1}^{m} \frac{\sum_{1}^{n}\left|S_{j}-1\right|}{n}+1}{m}
$$


where $\overline{\mathrm{ASL}}$ is average segregation level of $m$ segregated elements.

Then, the macrosegregation fluctuation level for $j$ segregated element in cooling zone ${ }_{i}$ can be computed as follows [21];

$$
\mathrm{FSL}_{j}=\max || S_{j_{\max }}|-| S_{j_{\min }} \|_{\text {zone }_{i}}
$$

where $S_{j_{\max }}$ and $S_{j_{\min }}$ are the maximum and minimum segregations of the segregated element $j$ within a cooling zone $i$, respectively. Consequently, the average macro-segregation fluctuation level for $m$ segregated elements in cooling zone $i$ “ $\overline{\text { FSL }}$ " can be computed as follows:

$$
\overline{\mathrm{FSL}}=\frac{\sum_{j=1}^{m} \max \left\|S_{j_{\max }}|-| S_{j_{\min }}\right\|_{\mathrm{zone}_{i}}}{m}
$$

The third criterion is the segregation quality number of element $j$ and can be calculated as follows [21]:

$$
\mathrm{SQN}_{j}=\frac{1}{\mathrm{ASL}_{j}}
$$

However, this criterion can be extended into $m$ segregated elements and can be rewritten as follows:

$$
\overline{\mathrm{SQN}}=\frac{\sum_{j=1}^{m} \frac{1}{\mathrm{ASL}_{j}}}{m}
$$

where $\overline{\mathrm{SQN}}$ is average segregation quality number of $m$ segregated elements.

As indicated in the previous study conducted by El-Bealy [21], the strand quality based on the cooling zones can be classified into three main areas as shown in Figure 7. The first area is mold quality area of segregated element $j$ “ASQN $\left.\right|_{\text {mold }}$ ” and it can be calculated as follows [21]:

$$
\left.\operatorname{ASQN}_{j}\right|_{\text {mold }}=\frac{1}{\left.\sum \mathrm{ASL}_{j}\right|_{\text {surface }}+\left.\sum \mathrm{ASL}_{j}\right|_{\mathrm{BAGF}}+\left.\sum \mathrm{ASL}_{j}\right|_{\mathrm{AAGF}}}
$$

The second quality area is spray quality area of segregated element $j$ “ASQN $\left.\right|_{\text {spray }}$ ” and it can be calculated as follows:

$$
\left.\operatorname{ASQN}_{j}\right|_{\text {spray }}=\frac{1}{\left.\sum_{N=1}^{N} \mathrm{ASL}_{j}\right|_{I}+\left.\mathrm{ASL}_{j}\right|_{I I}+\cdots+\left.\mathrm{ASL}_{j}\right|_{N}}
$$

Finally, the following equation was used to compute the central quality area of segregated element $j$ “ $\left.\mathrm{ASQN}_{j}\right|_{\text {center }}$ ”;

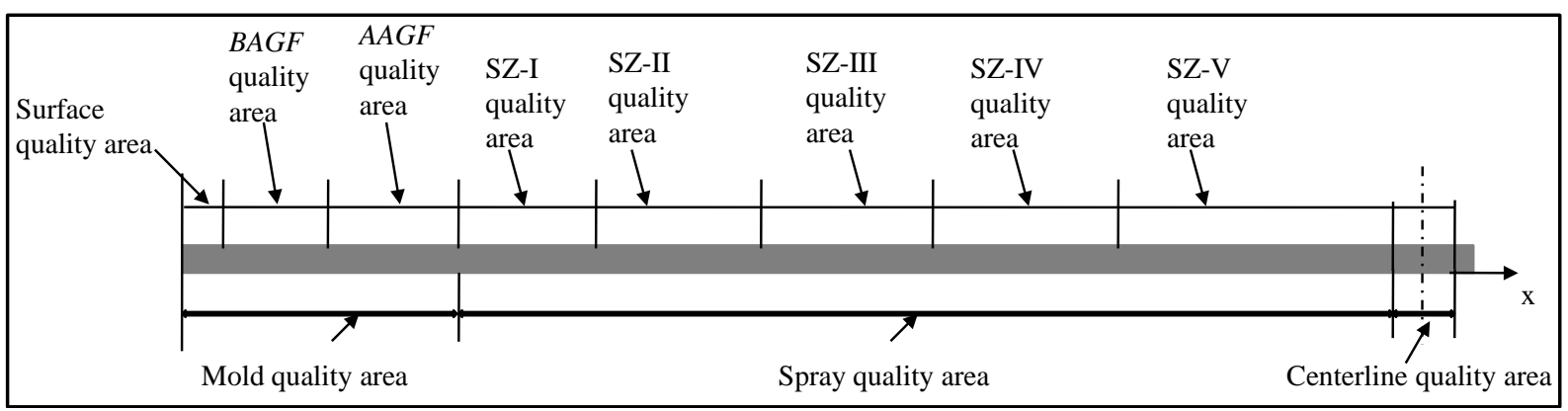

Figure 7. Schematic representation for strand quality regions [21]. 


$$
\left.\operatorname{ASQN}_{j}\right|_{\text {center }}=\frac{1}{\left.\sum \operatorname{ASL}_{j}\right|_{-c l}+\left.\operatorname{ASL}_{j}\right|_{+c}+\left.\operatorname{ASL}_{j}\right|_{c u}}
$$

The following equations were used in these computations to calculate average segregation quality criteria of $m$ segregated elements “ $\overline{\mathrm{ASQN}_{j}}$ ” of different cooling zones as follows,

$$
\begin{aligned}
& \overline{\left.\mathrm{ASQN}_{j}\right|_{\text {mold }}}=\frac{\sum_{j=1}^{m} \frac{1}{\left.\sum \mathrm{ASL}_{j}\right|_{\text {surface }}+\left.\sum \mathrm{ASL}_{j}\right|_{\mathrm{BAGF}}+\left.\sum \mathrm{ASL}_{j}\right|_{\mathrm{AAGF}}}}{m} \\
& \left.\overline{\mathrm{ASQN}_{j}}\right|_{\text {spray }}=\frac{\sum_{j=1}^{m} \frac{1}{\left.\sum_{N=1}^{N} \mathrm{ASL}_{j}\right|_{I}+\left.\mathrm{ASL}_{j}\right|_{I I}+\cdots+\left.\mathrm{ASL}_{j}\right|_{N}}}{m} \\
& \left.\overline{\operatorname{ASQN}_{j}}\right|_{\text {center }}=\frac{\sum_{j=1}^{m} \frac{1}{\left.\sum \mathrm{ASL}_{j}\right|_{-c l}+\left.\mathrm{ASL}_{j}\right|_{+c}+\left.\mathrm{ASL}_{j}\right|_{c u}}}{m}
\end{aligned}
$$

Equation (11) defines the average segregation quality criteria in different cooling regions in the mold zone for $m$ segregated elements, respectively. The mold cooling regions can be classified into three regions where the first one is surface region and the second region is before air gap formation "BAGF" whereas the third region is after air gap formation "AAGF".

Equation (12) defines the average segregation quality numbers in different spray cooling zones for $m$ segregated elements, respectively. The spray zones can be divided into $N$ cooling zones based on the caster design and based also on the type of cooling cycle, water flow rate and the nozzle outlet shape. This affects the macro-segregation formation and its distribution from zone to zone.

Finally, Equation (13) illustrates the average segregation quality numbers in various centerline regions for $m$ segregated elements. The central zone can be divided into two main regions. The first is the region before liquid pool length and it can be classified into two sub-regions of lower and upper slab sides. This can defined as average segregation level of lower side centre" $\mathrm{ASL}_{-c l}$ " and average segregation level of upper side centre " $\mathrm{ASL}_{-c u}$ ". The second main region is centerline region and its average segregation level can be defined as $\mathrm{ASL}_{+c}$. In this investigation, it is focused only on the final stage of spray zones and centerline zone and Equation (12) and Equation (13) were used in these computations to compute " $\overline{\mathrm{ASQN}_{j}}$ ".

However, the type and number of alloying elements needed to analyze and used to compute the slab qualities criteria accurately were selected based on the observed effect of steel composition on the susceptibility of the inter-

\begin{tabular}{|c|c|c|c|c|}
\hline G-I-A & G-I-B & G-I-C & G-I-D & G-II \\
\hline & & Internal cracks & & Surface cracks \\
\hline \multirow[t]{2}{*}{$C>0.6 \%$} & C from $0.17 \%$ to $0.24 \%$ & $C<0.16 \& C$ from & & C from 0.09 \\
\hline & & $0.25 \%$ to $0.6 \%$ & & to $0.17 \%$ \\
\hline $\mathrm{Si}>0.5 \%$ & $\mathrm{Mn}>1 \%$ & & Mo $>0.25 \%$ & $\mathrm{Al}>0.004 \%$ \\
\hline$S>0.025$ & $\mathrm{P}>0.03 \%$ & & & $\mathrm{Nb}$ from 0.02 \\
\hline $\mathrm{Cr}>3 \%$ & & & & to $0.04 \%$ \\
\hline \multirow[t]{2}{*}{$\mathrm{Ni}>1 \%$} & & & & $S>0.015$ \\
\hline & & & & $V>1 \%$ \\
\hline
\end{tabular}
dendritic crack formation [47]-[50]. The effect of steel composition on the different interdendritic cracks is tabulated in Table 4 [47]-[50]. The steel composition summarized in Table 1 shows that nominal $S$ concentration

Table 4. Alloying elements [47]-[50]. 
is greater than 0.025 wt pct. Therefore, the segregations of $C$ and $S$ elements should be analyzed to characterize the central quality.

\section{Model Predications \& Comparsions}

In order to calculate the segregation quality criteria, the present measurements were used to compute the segregation ratio distributions shown in Figures 3(a)-(c) by using Equation (1). Then, the Equations from (2) to (13) have been used to compute different segregation quality criteria of individual " $m=1$ " and multi " $m=2$ " segregated elements. Figures 8-11 show the average segregation level "ASL", fluctuation segregation level "FSL", segregation quality number "SQN" and its average "ASQN", respectively.

\subsection{Final Region of Spray Zones}

Figure 8(a) illustrates very slight "ASL" of carbon $(C)$ and sulfur $(S)$ in the final region of spray zones of first group samples. This results in a minimum FSL of two different elements associated with no effect of MSR technique as illustrated in Figure 9(a). It is observed also that there is sudden increasing in FSL of $S$ in the lower side without any changing in $C$ segregation. This results from high sensitivity of $S$ to segregate with any small displacement or roll misalignment. Another interesting result arises from the examination of segregation distributions of different slab sides where the different hypotheses subjected these sides or the displacement resulted from roll misalignment do not affect obviously the segregation patterns of different elements. This is due to a strong solid shell resistance associated with low constant casting speed [16] [17] [40]. Consequently, this affects directly SQN and its average ASQN where this effect keeps high qualities of different slab sides in the final region of spray zones as demonstrated in Figure 10(a) and Figure 11(a).

In second group, the casting speed changes during the casting process from 0.66 into $0.78 \mathrm{~m} / \mathrm{min}$. The fluctuations of ASL were observed by different levels of two elements in the final region of spray zones as shown in Figure 8(b). The fluctuations of $S$ segregation in this area are higher than those in the case of $C$ segregation
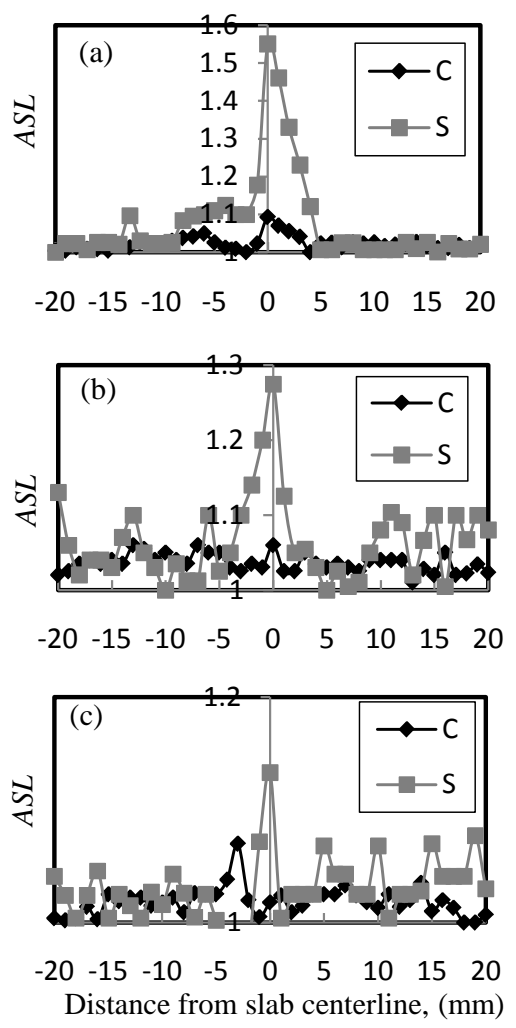

Figure 8. Variations of average macrosegregation level (ASL) for lower (-) and upper $(+)$ slab sides with different heats. 



Figure 9. Variations of maximum fluctuation macrosegregation level (FSL) for lower (-) and upper $(+)$ slab sides with different heats.

fluctuations. It is also concluded that the uncompleted application of MSR has observed effect on the FSL of $C$ and $S$ in this region as shown in Figure 9(b). Figure 10(b) shows that SQN continues to fluctuate in both slab sides and decreases the slab quality in different locations of final region of spray zones for both slab sides. Also, it is interesting to note that the comparison between ASQN in Figure 11(a), Figure 11(b) points out that ASQN of second group samples is smaller than in the case of first group samples of $C$ and $S$ segregations. This results from decreasing in the thermo-mechanical resistance of slab solid shell associated with declining of growth rate of slab solid shell resistance related to the increasing in casting speed [16] [17] [40]. This results in a high sensitivity to the thermo-mechanical stresses generated from different which affects directly the interdendritic solute liquid and therefore, affects the fluctuation segregation levels of different alloying elements [38] [40].

In the third group, the casting speed increases to be $0.78 \mathrm{~m} / \mathrm{min}$. This lengthens the liquid pool length. Therefore, the effective reduction length of MSR increases and MSR becomes significant to influence the segregation patterns of $C$ and $S$ in the final region of spray zones. This affects the ASL and increases also FSL of $C$, $S$ and their average as shown in Figure 8(c) and Figure 9(c), respectively. These figures point out also that the negative segregation of $C$ increases the average segregation level on the different slab sides. This negative segregation is considered also as a segregation defect and reduces the slab quality. This leads to a high fluctuation of SQN on both slab sides and decreases ASQN observably especially ASQN of $S$ as shown in Figure 10(c) and Figure 11(c), respectively, where Figure 11(c) illustrates also that ASQN decreases. Another interesting observatino arises from the examination of results plotted in Figure 8(b), Figure 8(c) where FSL in the third group is lower than in the case of second group. This is due to an uniform growth rate of solid shell resistance of solid shell associated with increasing in the homogeneity degree of cooling conditions between rolls due to constant casting used in this case [40] [51].

\subsection{Centerline Zone}

In the case of first group samples, MSR is not sufficient where the bulging shape line controls alone the sucking/squeezing mechanisms of mushy dendrites. This results in a negative segregation level close to the slab cen- 

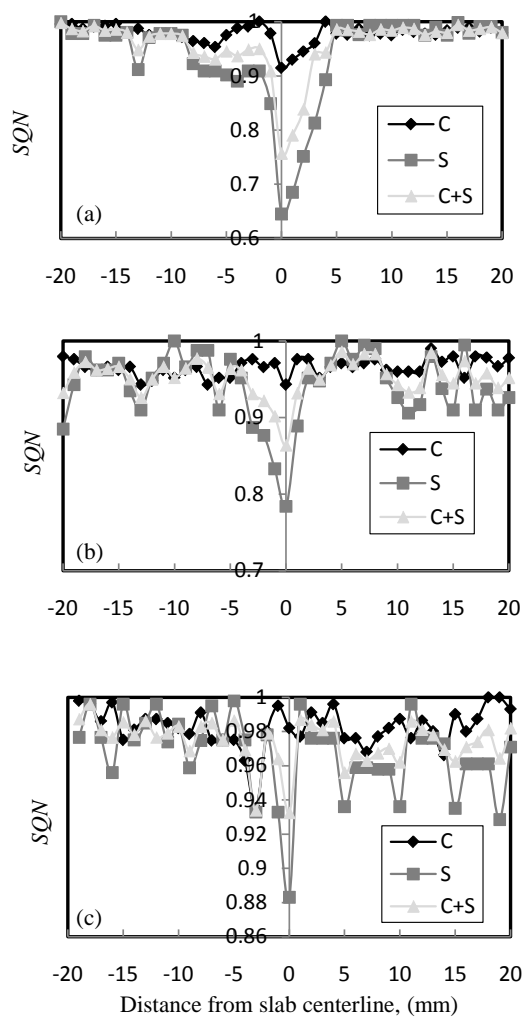

Figure 10. Variations of segregation quality number (SQN) for lower $(-)$ and upper $(+)$ slab sides with different heats.
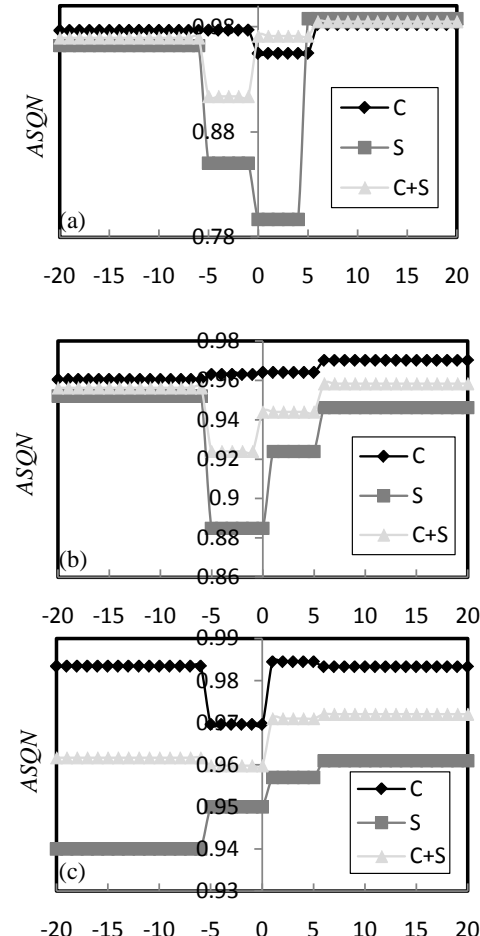

$\begin{array}{lllllllll}-20 & -15 & -10 & -5 & 0 & 5 & 10 & 15 & 20\end{array}$

Figure 11. Variations of average segregation quality number (ASQN) for lower (-) and upper (+) slab sides with different heats. 
terline and a high positive segregation level in the slab centerline of $C$ and $S$ as shown in Figure 3(a). Therefore, ASL of carbon and sulfur increase steeply into the high values as illustrated in Figure 8(a). It is also found that FSL increases in the region close to slab centerline followed by another increase in FSL in the slab centerline area as shown in Figure 9(a). In the region close to slab centerline, this figure shows that the S segregation level increases and this increasing enlarges steeply in the slab centerline. Consequently, SQN and its average ASQN of $C$ and $S$ reduce noticeably as shown in Figure 10(a) and Figure 11(a), respectively.

The variation in the casting speed of second group samples makes MSR somewhat is more influential. This is due to a natural result of the late impact of MSR. So, ASL and FSL values increase in the slab centerline zone as shown in Figure 8(c) and Figure 9(c), respectively. The model predications show also that FSL in upper and lower sides are different of $C$ and $S$ segregations. Also, the predications reveal that SQN and its average ASQN of $C$ and $S$ reduce in the centerline zone as shown in Figure 10(c) and Figure 11(c), respectively. The results show that ASQN are dissimilar of different sides and decreases steeply of $S$ segregation in the lower side. This is dissimilarity is due to different interdendritic strain hypotheses subjected to solid shell of different slab sides.

In the third group, the casting speed increases to be constant speed $(0.78 \mathrm{~m} / \mathrm{min})$ where MSR becomes sufficient and improve the centerline segregation significantly. This is due to a natural result of the early impact of MSR. Figure 8(c) and Figure 9(c) show that ASL decreases whereas FSL increases in the different regions of slab centerline zone, respectively. Also, it is interesting to note that there is an observable difference in FSL between the upper and lower slab sides as shown in Figure 9(c). The model predications reveal also that the value of FSL in the upper side is higher than its value in the lower side. With a complete application of MSR, SQN and its average ASQN of $C$ and $S$ improve and increase the central slab quality as seen in Figure 10(c) and Figure 11(c), respectively. Also, it is interesting to note that ASQN of different slab sides is different in this zone. This is due to a difference between the distributions of $C$ and $S$ segregations of the upper and lower slab sides as shown in Figure 3(c).

\section{General Discussion}

Before proceeding further, it is appropriate to discuss the mechanism of centerline segregation formed during final stages of slab solidification with respect to the shape of bulging line and its level illustrated in Figure 6. These depend on the solidification behavior, casting and cooling conditions as well as therefore their coupled effect on the movement of mushy dendrites in and out [38] [39].

Figure 6 shows that the slab moves horizontally and the solid shell of upper slab side bulges in close to the first roll (MSR1). This pushes the mushy dendrites in the direction of slab centre and draws the steel liquid from hotter region in the liquid pool into early stages of solidification in the mushy zone. With increasing the negative bulging, the opening between dendrites increases through which the interdendritic liquid just blow the liquidus isotherm flows in against little resistance. Also, the ferrostatic pressure helps to push the interdendritic liquid into cooler regions in the mushy zone to segregate [38] [39]. This mechanism increases the possibility of fluctuated segregation phenomenon in the final region of spray zones whereas it increases the chance of negative segregation areas close to the slab centerline as shown in Figure 4(a). The negative bulging decreases gradually and the effect of this mechanism on the mushy dendrites declines until the location of zero bulging between a pair of rolls as illustrated in Figure 6 [38] [39]. Then, the solid shell starts to bulges out and dendrites draw out. This sucks the interdendritic liquid to flow from the upper liquid pool areas into the slab centerline area against a high ferrostatic pressure to form the centerline segregation as shown in the mechanism $C_{S}$ in Figure 5. However, the bulging profile of lower side differs from its profile in the upper side as shown in Figure 6. This results in different effects on the fluid flow pattern of steel liquid. Subsequently, the coupled effect of fluid flow patterns influences the macro-segregation distribution and its resultant controls the level of this segregation. This agrees well with approaches proposed by El-Bealy [38], and Flemings [39], as well as the measurements by Jacobsson et al. [32]. El-Bealy [38], also concluded that the segregation distributions of upper and lower slab sides are different as seen in Figure 4(a). This is due to different interdendritic strain hypotheses where ASL increases steeply from small into high positive value due to the above mechanism of centerline segregation as shown in Figure 6(a). Consequently, FSL increases steeply into value of 0.175 shown in Figure 7(a) whereas SQN and its average ASQN drop into minimum values of 0.864 and 0.994 as illustrated in Figure 10(a) and Figure 11(a), respectively. These are because the effect of MSR is ineffective. 
When a solidifying shell of continuously cast steel slabs is deformed by applying MSR to compensate the positive bulging as shown in Figure 1 and Figure 6, the steel liquid in the liquid pool will be squeezed into the interdendritic areas between the dendrites as shown in mechanism A in Figure 5. This mechanism can be defined as squeezing segregation and results from reduction in the positive bulging of solid shell. This reduces the centerline segregation by different levels based mainly on the effective length reduction of MSR, steel composition, slab side, magnitude of solid shell resistance at initial and its growth during MSR effective length. Since its composition differs from that of the dendrites inevitably, the fluctuated macrosegregation phenomenon will form in the final region of spray zones between the dendrites as shown in Figure 4(b) and Figure 4(c). The concentrated reduction ratio by using roll alignment increases this fluctuated segregation phenomenon of alloying elements by different levels. This is based mainly on the reduction characteristics especially the total effective reduction length as shown in Figure 4(b) and Figure 4(c).

In the case of group 2, MSR may begin to subject the slab solid shell at MSR2 location whereas in the case of group 3 samples, MSR may begins early and subjected the solid shell at location MSR1 as shown in Figure 1, Figure 5 and Figure 6 . The level of segregation of different elements segregates depends mainly on MSR pattern and the metallurgical properties of alloying elements. These appear in ASL and FSL in Figure 8(b), Figure 8(c) and Figure 9(b), Figure 9(c), respectively. Also, the squeezing mechanism of MSR may push the free crystals into the slab centerline area. This reduces the permeability of interdendritic liquid flow from the interdendritic areas between the dendrites and from the hotter regions in liquid pool above. The reduction in the permeability in the slab centerline area increases when MSR subjects the slab solid shell in the early stages exactly below the liquid pool end in right location (MSR1) as shown in Figure 5. This agrees well with observations of Jacobsson et al. [21]. Also, they concluded that casting speed and MSR applied location control the structure changes in the slab centerline area and increase the length of equaixed crystals in this area. Finally, the formation of narrow zone of equaixed crystals gives explanations of centerline porosity shown in Figure 3(b). This porosity appears in slab centerline area as small spaced areas and these interdendritic spaces are not connected. This agrees will the segregates measurements performed by Jacobi [52]. He concluded that the porosity formed due to unsuitable and different growth rates of solid shell along the slab broad face. Evidence for these conclusions, it can be founded in Figure 10(b), Figure 10(c) and Figure 11(b), Figure 11(c). These figures reveal that SQN and its average ASQN reduce the slab quality in final stage of spray zone by different reduction based on the casting speed pattern. Consequently, the results from these figures point out also that the slab quality increases steeply in the slab centerline area due to applying MSR and the slab quality depends essentially on the casting speed.

However, the representative calculations of quality criteria shown in Figures 8(a)-(c) to Figures 11(a)-(c) are found to be the most important criteria in determining the slab qualities qualitatively and quantitatively. These results and previous work [21] [53]-[58], support the consistent relationship between the macrosegregation levels of different elements and slab qualities where two segregated elements should be analyzed. Figures 11(a)-(c) exhibit that the slab qualities increase in the final region of spray zones and centerline zone with decreasing the segregations of carbon and sulfur elements. Also, $\left.\overline{\mathrm{ASQN}_{j}}\right|_{N}$ of $N$ zones for multi segregated elements is higher than ASQN of $S$ whereas $\left.\overline{\operatorname{ASQN}_{j}}\right|_{N}$ is smaller than ASQN of $C$. This is due to high sulfur segregations where the averages of slab qualities reduce by different levels based on the mechanical soft reduction characteristics. Also, there is an observed difference in $\left.\overline{\mathrm{ASQN}_{j}}\right|_{\text {central }}$ between upper and lower slab sides in the centerline zone due to different segregations. These results support by Jacobi [52], conclusions. He concluded that the growth rates of solid shell of different slab sides along the slab broad faces are different which results in different segregated patterns.

\section{Summary and Conclusions}

From the combined segregation measurements of plant trails and computer aided analysis of quality criteria, major new findings have been observed on the mechanical soft reduction "MSR" and its influencing on the level of central quality. The most important results are the apparent effect of casting speed on the segregation distribution and its fluctuation in final stage of spray and centerline zones. In the final stage of spray zones, MSR increases the fluctuations of positive sulfur and negative carbon elements for upper and lower sides. This reduces the quality in this region whereas increases the slab central quality by different levels. 
A quality segregation model of $m$ segregated elements has developed and utilized to calculate average macrosegregation level criterion "ASL", its fluctuation level "FSL", segregation quality number "SQN" and its average of different cooling zones "ASQN". Based on the steel composition, it has been shown that segregation model of two segregated elements is essential for accurate quantitative computation of segregation quality criteria. In this case, recommendations have made to analyze the sulfur segregation in addition to carbon analysis especially when the sulfur content is greater than that is allowed in the references. Subsequently, the quality model can evaluate accurately the different effects of mechanical soft reduction technique on the various qualities at different locations of central regions in continuously cast steel slabs qualitatively and quantitatively.

Although, the model predications are generally supported by the pervious experimental results of mechanical soft reduction and its effect on the central segregation level, it is necessary to create more experimental work by analyzing the segregation of different alloying elements especially that increase the possibility of defects formations. Another important aspect of the future work is to couple the present model with simulating models of macrosegregation to predict directly the different slab qualities. This will guide us to define on line the low quality regions and then to save solutions to improve these qualities automatically. In this future work, we may prove the parameters affected the stages of solidification defects that depend on the thermo-metallurgical and mechanical mechanisms subjected to the solid shell of continuously cast steel slabs.

\section{Acknowledgements}

The author wishes to express his sincere gratitude to Prof. Merton Flemings, Massachusetts Institute of Technology (MIT), former Head of Department of Materials Science and Engineering, Massachusetts, USA for his early pioneer work in the solidification processes, macro/micro-segregation and solidification cracks fields which guides the author to several facts in these fields. The author wishes also to express his sincere gratitude to Prof. Hasse Fredriksson and Prof. Du Sichen, both are with, Royal Institute of Technology, Div. of Casting of Metals, Department of Materials Science and Engineering, Stockholm, Sweden for his considerable supervision, guidance, helpful discussions throughout this work and valuable assistance. The author the co-operation and assistance of operating personnel the co-operation OxelÖsund Works, OxelÖsund, Sweden, especially Dr. Anders Lagersted, former Doctoral student in the same department in KTH for supplying the experimental measurements and results are also gratefully acknowledged. The author is also especially grateful for financial support of Companies' Chair of the Swedish Iron Masters Association, Stockholm, Sweden. Finally, the co-operation and assistance of operating personnel especially Eng. Fareed Ashraf Khan, Research Engineering, in the same division during this work is also gratefully acknowledged.

\section{References}

[1] Samarasekera, I.V., Anderson, D.L. and Brimacombe, J.K. (1982) The Thermal Distortion of Continuous-Casting Billet Molds. Metallurgical and Materials Transactions B, 13, 91-104. http://dx.doi.org/10.1007/BF02666960

[2] Samarasekera, I.V. and Brimacombe, J.K. (1982) The Influence of Mold Behavior on the Production of Continuously Cast Steel Billets. Metallurgical and Materials Transactions B, 13, 105-116. http://dx.doi.org/10.1007/BF02666961

[3] Lally, B., Biegler, L.T. and Henein, H. (1991) Optimization and Continuous Casting: Part I. Problem Formulation and Solution Strategy. Metallurgical and Materials Transactions B, 22, 641-648. http://dx.doi.org/10.1007/BF026790(19

[4] Lally, B., Biegler, L.T. and Henein, H. (1991) Optimization and Continuous Casting: Part II. Application to Industrial Casters. Metallurgical and Materials Transactions B, 22, 649-659. http://dx.doi.org/10.1007/BF02679020

[5] El-Bealy, M. and Fredriksson, H. (1994) On the Formation of a Fluctuated Macrosegregation Phenomenon in Continuous Casting Processes. Scandinavian Journal of Metallurgy, 23, 140-150.

[6] Meng, Y. and Thomas, B.G. (2003) Heat-Transfer and Solidification Model of Continuous Slab Casting: CON1D. Metallurgical and Materials Transactions B, 34, 685-705. http://dx.doi.org/10.1007/s11663-003-0040-y

[7] Li, Y. and Thomas, B.G. (2004) Thermomechanical Finite-Element Model of Shell Behavior in Continuous Casting of Steel. Metallurgical and Materials Transactions B, 35, 1151-1172. http://dx.doi.org/10.1007/s11663-004-0071-z

[8] Zhu, L.G. and Kumar, R.V. (2007) Modeling of Steel Shrinkage and Optimization of Mould Taper for High Speed Continuous Casting. Ironmaking \& Steelmaking, 34, 76-82. http://dx.doi.org/10.1179/174328106X118152

[9] El-Bealy, M.O. (2008) Fluctuated Macrosegregation Phenomenon “FMP” New Technique to Evaluate the Mould Heat Flux in Continuous Casting Processes Proceed. 6th European Conference on Continuous Casting, Riccione, 3-6 June 2008, 229-234. 
[10] Nassar, H., Korojy, B. and Fredriksson, H. (2009) A Study of Shell Growth Irregularities in Continuously Cast 310S Stainless Steel. Ironmaking \& Steelmaking, 36, 521-528. http://dx.doi.org/10.1179/174328109X445714

[11] Manojlovie, R. (2013) Mathematical Modeling of Solidification Process of Continuous Casting Steel Slabs. Journal of Chemical Technology and Metallurgy, 48, 419-427.

[12] Alizadeh, M., Edris, H. and Shafyei, A. (2006) Mathematical Modeling of Heat Transfer for Steel Continuous Casting Process. International Journal of ISSI, 3, 7-16.

[13] Xu, D., Jones Jr., W.K., Evans, J.W. and Cook, D.P. (1998) Mathematical and Physical Modeling of Systems for Metal Delivery in the Continuous Casting of Steel and DC Casting of Aluminum. Applied Mathematical Modelling, 22, 883893. http://dx.doi.org/10.1016/S0307-904X(98)10029-X

[14] Bock, H., Kostina, G.E., Phu, H.X. and Rannacher, R. (2005) Modeling, Simulation and Optimization of Complex Processes. Spinger-Verlag, Berlin. http://dx.doi.org/10.1007/b138710

[15] Zhang, L. (2006) Fluid Flow, Heat Transfer and Inclusion Motion in Molten Steel Continuous Casting Tundishes. 5th International Conference on CFD in the Process Industries, CSIRO, Melbourne, 13-15 December 2006, 1-9.

[16] Miyazawa, K. and Schwerdtferger, K. (1979) Computation of Bulging of Continuously Cast Slabs with Simple Bending Theory. Ironmaking \& Steelmaking, 6, 68-74.

[17] El-Bealy, M. (1997) Fluctuated Cooling Conditions and Solid Shell Resistance in Continuously Cast Steel Slabs. Canadian Metallurgical Quarterly, 36, 203-222. http://dx.doi.org/10.1179/cmq.(1997.36.3.203

[18] Won, Y., Yeo, T.-J., Seol, D. and Oh, K. (2000) A New Criterion for Internal Crack Formation in Continuously Cast Steels. Metallurgical and Materials Transactions B, 31, 779-794. http://dx.doi.org/10.1007/s11663-000-0115-y

[19] Son, I.H., Lee, J.D., Choi, S., Lee, D.I. and Im, Y.T. (2008) Deformation Behavior of the Surface Defects of Low Carbon Steel in Wire Rod Rolling. Journal of Materials Processing Technology, 201, 91-96. http://dx.doi.org/10.1016/j.jmatprotec.2007.11.129

[20] El-Bealy, M.O. (2013) A Formation of Macrosegregation Phenomenon for Interdendritic Crack Occurrence during Solidification in Continuous Casting of Steel. Metallurgical and Materials Transactions B, 45, 988-1017. http://dx.doi.org/10.1007/s11663-013-9911-z

[21] El-Bealy, M.O. (2013) New Macrosegregation Criteria for Quality Problems in Continuously Cast Steel Slabs. Ironmaking \& Steelmaking, 40, 559-570. http://dx.doi.org/10.1179/1743281212Y.0000000085

[22] Kumar, S., Meech, J.A., Samarasekera, I.V. and Brimacombe, J.K. (1993) Knowledge Engineering an Expert System to Troubleshoot Quality Problems in the Continuous Casting of Steel Billets. Iron \& Steelmaker, 20, 29-36.

[23] Filipic, B. and Saler, V. (1998) Multiobjective Optimization with Linguistic Variables. Proceedings of 6th European Congress on Intelligent Techniques and Soft Computing-EUFIT'98, Aachen, 444-449.

[24] Brimacombe, J.K. (1999) The Challenge of Quality in Continuous Casting Processes. Metallurgical and Materials Transactions A, 30, 1899-1912. http://dx.doi.org/10.1007/s11661-999-0001-4

[25] Cheung, N. and Garcia, A. (2001) The Use of Heuristic Search Technique for the Optimization of Quality of Steel Billets Produced by Continuous Casting. Engineering Applications of Artificial Intelligence, 14, 229-238. http://dx.doi.org/10.1016/S0952-(1976(00)00075-0

[26] Santos, C.A., Spim Jr., J.A., Ieradi, M.C.F. and Garcia, A. (2002) The Use of Artificial Intelligence Technique for the Optimization of Process Parameters Used in the Continuous Casting of Steel. Applied Mathematical Modeling, 26, 1077-1092. http://dx.doi.org/10.1016/S0307-904X(02)00062-8

[27] Rabiser, R. and Hungana, D. (2007) Software Engineering and Advanced Applications. 33th Euromicro Conference, Lübeck, 28-31 August 2007, 219-228.

[28] Kolev, K., Klodt, M., Brox, T. and Cremers, D. (2009) Continuous Global Optimization in Multiview 3D Reconstruction. International Journal of Computer Vision, 84, 80-96. http://dx.doi.org/10.1007/s11263-009-0233-1

[29] López, A.R., Cortés, D.S., Pardavé, M.P., Romo, M.A.R. and López, R.A. (2010) Computational Algorithms to Simulate the Steel Continuous Casting. International Journal of Minerals, Metallurgy, and Materials, 17, 596-606.

[30] Collur, M.W. (Private Communications) (1996) Simulation of Mold Heat Flux by Using CON1D Model. Allegheny Ludlum Corp., Brackenridge.

[31] Lagerstedt, A. (2004) On the Shrinkage of Metals and Its Effect in Solidification Processing. Ph.D. Thesis, Royal Institute of Technology, Stockholm.

[32] Jacobsson, N., Raihle, C.-M. and Leskine, N. (1992) Liquid Pool Measurements: A Tool to Improve Internal Quality during Continuous Casting. Scandinavian Journal of Metallurgy, 21, 172-180.

[33] Ogibayashi, S., Uchimura, M., Isobe, K., Maede, H., Nishihara, Y. and Sato, S. (1990) Improvement of Center Segregation in Continuously Cast Blooms by Soft Reduction in the Final Stage of Solidification. Proceedings of the 6th International Iron and Steel Congress, Nagoya, 271-278. 
[34] Ayata, K., Koyama, S., Nakata, H., Kawasaki, S., Enina, K. and Hata, T. (1990) Improvement of Center Segregation in Continuously Cast Bloom by Hard Reduction Near the Crater End. Proceedings of the 6th International Iron and Steel Congress, Nagoya, 279-284.

[35] El-Bealy, M. and Fredriksson, H. (1996) Modeling of Peritectic Reaction and Macrosegregation in Casting of Low Carbon Steel. Metallurgical and Materials Transactions B, 27, 999-1014. http://dx.doi.org/10.1007/s11663-996-0015-x

[36] Alberny, R. and Birat, J.P. (1977) Continuous Casting of Steel. The Metals Society of IRSID, Biarritz, 116-124.

[37] Westin, L. (1977) Continuous Casting of Steel. The Metals Society of IRSID, Biarritz, 158-161.

[38] El-Bealy, M.O. (2013) Spray Cooling Pattern and Microthermomechanical Rigidity Criterion for Improving Inner Quality in Continuously Cast Steel Slabs. Ironmaking \& Steelmaking, 40, 167-188. http://dx.doi.org/10.1179/1743281211Y.0000000070

[39] Flemings, M.C. (1991) Behavior of Metal Alloys in the Semisolid State. Metallurgical and Materials Transactions A, 22, 957-998. http://dx.doi.org/10.1007/BF02661090

[40] El-Bealy, M. (1995) On the Mechanism of Halfway Cracks and Macrosegregation of Continuously Cast Steel Slabs. Scandinavian Journal of Metallurgy, 24, 63-80.

[41] Brimacombe, J.K. and Sorimachi, K. (1977) Crack Formation in the Continuous Casting of Steel. Metallurgical and Materials Transactions B, 8, 489-505. http://dx.doi.org/10.1007/BF02696937

[42] Sandberg, H. (1973) Influence the Alloying Elements on Partition Coefficient of Carbon Steels. Scandinavian Journal of Metallurgy, 2, 233-239.

[43] Yn, L. (2000) FEM Analysis of Bulging between Rolls in Continuous Casting. Master Thesis, University of Illinois, UIUC, Illinois.

[44] El-Bealy, M.O. (2011) Air-Water Mist and Homogeneity Degree of Spray Cooling Zones for Improving Quality in Continuous Casting of Steel. Steel Research International, 82, 1187-1296. http://dx.doi.org/10.1002/srin.201000301

[45] El-Bealy, M.O. (2013) Li Mold Thermo-Mechanical Rigidity Criterion for Surface Quality of Continuous Casting of Steel. Materials Sciences and Applications, 4, 39-51. http://dx.doi.org/10.4236/msa.2013.41006

[46] Megson, T.H.G. (2005) Structural and Stress Analysis. Butterworth-Heinemann, Oxford.

[47] Ende, H.V. and Vogt, G. (1972) Effects of Alloying Elements on Cracking during Continuous Casting. The Journal of the Iron and Steel Institute, 210, 889-994.

[48] Hall, H.F. (1936) Strength and Ductility of Cast Steel during Cooling from the Liquid State in Sand Molds. 2nd Report of Steel Casting Research Committee. Iron and Steel Institute, London.

[49] Webster, J.S. and Graham, C. (1976) Operational Experience on the Continuous Bloom Casting Machine at South Teesside Works. Proceedings of Metals Society/IRSID Conference on Continuous Casting, Biarritz.

[50] Aketa, Y. and Ushijima, K. (1962) The Importance of Two Zones of Low Ductility in Steel Is Demonstrated by This Approach. Tetsu-to-Hagane, 2, 22-31.

[51] Alvarez de Toledo, G., Lainez, J. and Cirión, J.C. (1993) Model Optimization of Continuous Casting Steel Secondary Cooling. Materials Science and Engineering: A, 173, 287-291. http://dx.doi.org/10.1016/0921-5093(93)90230-C

[52] Jacobi, H.F. (2003) Investigation of Centerline Segregation and Centerline Porosity in CC-Slabs. Steel Research, 74, 667-678.

[53] Takeuchi, E. and Brimacombe, J.K. (1985) Effect of Oscillation-Mark Formation on the Surface Quality of Continuously Cast Steel Slabs. Metallurgical and Materials Transactions B, 16, 605-625. http://dx.doi.org/10.1007/BF02654859

[54] Takeuchi, E. and Brimacombe, J.K. (1984) The Formation of Oscillation Marks in the Continuous Casting of Steel Slabs. Metallurgical and Materials Transactions B, 15, 493-509. http://dx.doi.org/10.1007/BF02657380

[55] Brimacombe, J.K., Weinberg, F. and Hawbolt, E.B. (1979) Formation of Longitudinal, Midface Cracks in Continuously-Cast Slabs. Metallurgical and Materials Transactions B, 10, 279-292. http://dx.doi.org/10.1007/BF02652472

[56] Korothov, K.P., et al. (1960) The Continuous Casting of Steel in Commercial Use. Pergamon Press, Oxford.

[57] Kohno, T., Shima, T., Kuwabara, T., Yamamoto, T. and Tsuneoka, A. (1982) Formation of Macrosegregation in Continuous Casting of Steel. Transactions on ISS, 2, 133-137.

[58] Irving, W.R., Perkins, A. and Gray, R.J. (1984) Effect of Chemical, Operational and Engineering Factors on Segregation in Continuously Cast Slabs. Ironmaking \& Steelmaking, 11, 146-151. 


\section{Nomenclatures}

$\mathrm{ASL}_{j}$ : average macrosegregation level for segregated element $j$.

$\overline{\mathrm{ASL}}$ : average macrosegregation level for $m$ segregated elements.

$\left.\mathrm{ASL}_{j}\right|_{I}$ : average macrosegregation level for $j$ segregated element in cooling region $I$.

$\left.\mathrm{ASQN}_{j}\right|_{\text {mold }}$ : average segregation quality number of segregated element $j$ in mold zone.

$\left.\mathrm{ASQN}_{j}\right|_{\text {spray }}$ : average segregation quality number of segregated element $j$ in spray zone.

$\left.\mathrm{ASQN}_{j}\right|_{\text {center }}$ : average segregation quality number of segregated element $j$ in central zone.

$\left.\overline{\mathrm{ASQN}_{j}}\right|_{\text {mold }}$ : average segregation quality number of segregated elements $m$ in mold zone.

$\left.\overline{\operatorname{ASQN}_{j}}\right|_{\text {spray }}$ : average segregation quality number of segregated elements $m$ in spray zone.

$\left.\mathrm{ASQN}_{j}\right|_{\text {center }}$ : average segregation quality number of segregated elements $m$ in central zone.

$\mathrm{FSL}_{j}$ : macrosegregation fluctuation level of segregated element $j$.

$\overline{\text { FSL }}$ : macrosegregation fluctuation level of segregated elements $m$.

${ }^{N} K_{C}^{m}$ : partition coefficient of carbon for component $m$, in an $N$-component system.

$S_{j}$ : macrosegregation ratio of element $i$.

$S_{j \min }$ : minimum segregation ratio of $j$ segregated element in cooling zone $i$.

$S_{\text {jmax }}$ : maximum segregation ratio of $j$ segregated element in cooling zone $i$.

$\mathrm{SQN}_{j}$ : segregation quality number of segregated element $j$.

$\overline{\mathrm{SQN}}$ : segregation quality number of segregated elements $m$.

$v$ : casting speed (m/min).

\section{Greek Symbols}

$\chi_{\text {mea }_{j}}$ : measured concentration of element $j \quad$ (wt\%).

$\chi_{o_{j}}$ : nominal concentration of element $j$ (wt $\%$ ). 
Scientific Research Publishing (SCIRP) is one of the largest Open Access journal publishers. It is currently publishing more than 200 open access, online, peer-reviewed journals covering a wide range of academic disciplines. SCIRP serves the worldwide academic communities and contributes to the progress and application of science with its publication.

Other selected journals from SCIRP are listed as below. Submit your manuscript to us via either submit@scirp.org or Online Submission Portal.
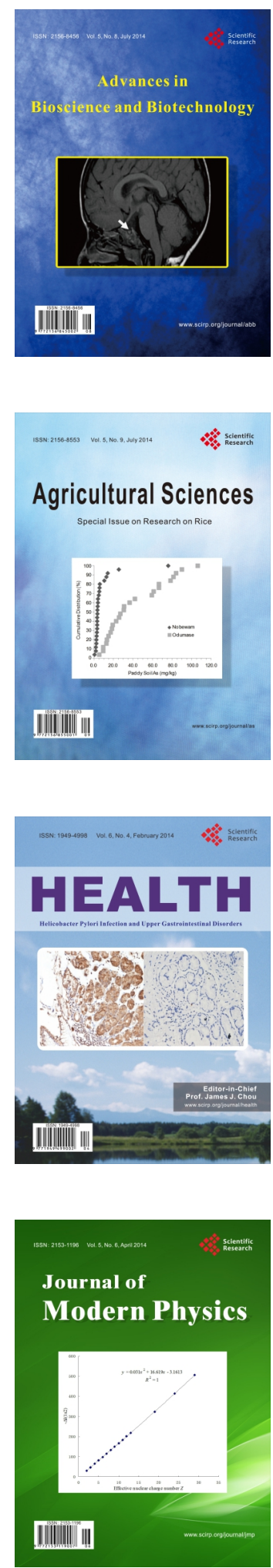
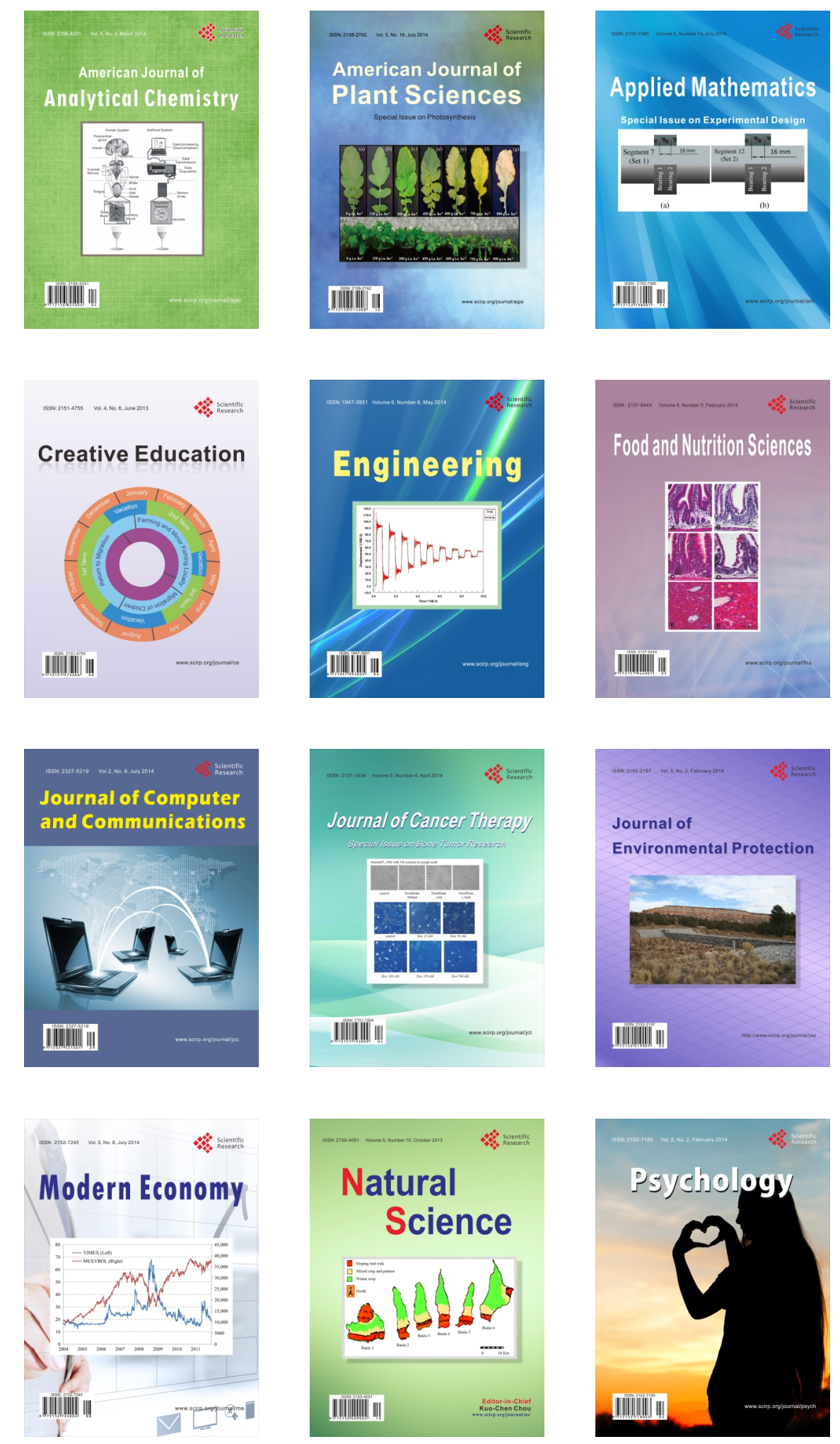